\title{
АСИММЕТРИЧНОЕ РАЗВИТИЕ РЕГИОНАЛЬНЫХ РЫНКОВ ТРУДА В УСЛОВИЯХ НИЗКИХ ТЕМПОВ ЭКОНОМИЧЕСКОГО РОСТА
}

\author{
(C) 2020 Блинова Татьяна Викторовна \\ доктор экономических наук, главный научный сотрудник \\ Институт аграрных проблем Российской академии наук, Россия, Саратов \\ E-mail: ruandre@mail.ru
}

Проведено исследование межрегиональной дифференциации российского рынка труда, рассмотрена его кластерная структура, выделены относительно однородные группы регионов по уровню безработицы, оценены межрегиональные колебания ключевых индикаторов. Выявлены причины асимметричного поведения регионов РФ на рынке труда, что позволяет получить необходимую информацию для оценки региональных рисков роста безработицы в условиях низких темпов экономического роста или рецессии.

Ключевые слова: рынок труда, безработица, регионы России, асимметрия, рецессия

\section{Введение}

Исследования пространственных различий ключевых индикаторов рынка труда, а также причины регионального неравенства по доходам и заработной плате широко представлены в российской и зарубежной литературе [1,2]. В одних работах рассматриваются территориальные и возрастные особенности распределения безработицы в европейских странах [3]. Другие адресованы проблемам занятости, безработицы и рынка труда в субъектах Российской Федерации [4,5]. Проведенные исследования показывают, что экономическое пространство национального рынка труда России отличается высокой гетерогенностью. Так, между федеральными округами РФ различие по уровню безработицы почти четырехкратное, его значения колеблются от 2,8\% в Центральном до 10,6\% в Северо-Кавказском ФО. Дифференциация региональных рынков труда внутри федеральных округов также высокая. Например, уровень безработицы в СевероКавказском ФО колеблется от 4,8\% (Ставропольский край) до 26,0\% (Республика Ингушетия), в Сибирском ФО от 4,2\% (Красноярский край) до 11\% (Республика Тыва), Дальневосточном ФО от 4,1\% (Хабаровский край) до 9,0\% (Республика Бурятия). Сравнительный анализ показывает, что еще более значительными являются различия на рынке труда между субъектами РФ, где разброс и колебания уровня безработицы составляют от $1,3 \%$ в Москве и $1,4 \%$ в Санкт-Петербурге до $26,0 \%$ в Республике Ингушетии и $13,4 \%$ в Чеченской Республике [6].

Как справедливо отмечают ученые, «россий- ский рынок труда существует как система слабо связанных между собой территориальных/локальных рынков» [7, с. 136], имеющих сложные механизмы взаимодействия. Авторы акцентируют внимание на том, что реакция региональных рынков труда на изменения в макроэкономических условиях также может быть разной. Однако механизм подстройки к экономическим шокам преимущественно за счет падения реальной заработной платы при незначительном изменении уровня занятости характерен для подавляющего большинства регионов России. Именно по этой причине в условиях финансового кризиса 2008-2009 гг. и экономической рецессии 2015-2016 гг. рост безработицы не был катастрофическим, а падение занятости не оказалось обвальным. Вместе с тем во многих регионах РФ ситуация на рынке труда существенно отличается от среднероссийской как в период кризиса, так и последующего восстановительного роста.

Целью статьи является исследование межрегиональной дифференциации российского рынка труда, выявление факторов риска, и обоснование причин разнотипных поведенческих реакций на макроэкономические изменения. Информационную базу исследования составили статистические данные, размещенные на официальном сайте Росстата.

\section{Обзор литературы}

Поведение ключевых индикаторов рынка труда на разных стадиях бизнес-цикла в различных странах и регионах является предметом многочисленных дискуссий как в россий- 
ской, так и зарубежной научной литературе [8, $9,10,11]$. Несмотря на большое количество работ, посвященных вопросам занятости, безработицы, рынка труда, проблемы межрегиональной дифференциации, источники и факторы риска, особенности поведенческих реакций региональных рынков труда на макроэкономические изменения, остаются недостаточно изученными. Исследователи отмечают важную роль институтов, характера взаимодействия между экономическими шоками и ситуацией, сложившейся на рынке труда перед началом кризиса. Не меньший вклад в формирование межрегиональных контрастов вносят особенности демографической ситуации в регионе, уровень образования и структура экономики по видам экономической деятельности. Подчеркивается нелинейный характер поведения параметров рынка труда как в условиях рецессии, так и на стадии восстановительного роста. В ряде работ изучались ключевые детерминанты пространственной неоднородности национального рынка труда [5,12].

Исследования влияния макроэкономических изменений на поведение основных индикаторов российского рынка труда и степень его межрегиональной дифференциации развивались по многим направлениям. Однако основное внимание отечественных авторов было сосредоточено на специфических особенностях российской модели рынка труда и механизмах подстройки к макроэкономическим шокам. Рассматривая проблемы российского рынка труда, выделяя этапы его развития, изучая влияние структурных сдвигов, ученые отмечают, что «едва ли не главной функциональной особенностью российской модели рынка труда» можно считать «слабую сенситивность занятости к колебаниям в объемах производства» [7, с. 10]. Другая особенность состоит в гибкости российской модели рынка труда и способности адаптироваться к изменениям преимущественно за счет «ценовой подстройки» [7, с. 15]. Не менее важной характеристикой российского рынка труда является высокая гетерогенность его региональной структуры, которая определяет специфику поведенческих реакций ключевых индикаторов на изменения. Являясь фундаментальной особенностью, межрегиональные различия устойчивы во времени, оценки, выполненные с использованием индексов Джини, Тейла, Морана, свидетельствуют, что они сохраняются на всех стадиях бизнес-цикла, сокращаясь в период кризиса и увеличиваясь в условиях восстановительного роста [11]. В отдельных регионах в период кризиса экономические шоки, влияющие на спад занятости и рост безработицы, имеют не краткосрочные, а длительные последствия.

\section{Результаты исследования}

Проведенные исследования показывают, что относительно низкий уровень безработицы в России, который составляет 4,6\% по данным Росстата на декабрь 2019 г. [13], не отражает реальную ситуацию на рынке труда. Сохраняется скрытая безработица, неформальная занятость, кроме того, представители отдельных социальных групп населения вынуждено или добровольно не вовлечены в сферу занятости, профессионального образования или переподготовки (NEET - Not in Employment, Education and Training). Наиболее высокий уровень скрытой безработицы характерен для сельских поселений. Среди основных причин следует выделить, во-первых, слабую доступность центров занятости для сельского населения из-за их отдаленности и отсутствия развитой дорожнотранспортной инфраструктуры сельских территорий. Во-вторых, немаловажным фактором является узость сферы приложения труда в сельской местности, низкая диверсификация аграрной экономики, структуры занятости и источников дохода, а также недостаточное развитие сегмента несельскохозяйственных видов экономической активности на сельском рынке труда [10]. В - третьих, высокие транзакционные издержки, низкий уровень оплаты труда, отсутствие доступного рынка арендного жилья, наличие приусадебных хозяйств, сдерживают мобильность потенциальной рабочей силы. B-четвертых, не все сельчане, потерявшие работу, готовы переехать в город из-за приверженности к традиционному укладу и сельскому образу жизни. В силу указанных и других причин уровень фактической сельской безработицы (6,5\%), измеряемый по методологии МОТ, значительно выше городской $(3,8 \%)$, а доля сельских жителей среди безработных составляет более трети $(33,4 \%)$ [6], в то время как в структуре населения России только 25,4\% [14]. Территории с высоким удельным весом сельского населения относятся к сегментам повышенного риска на рынке труда. Различия между регионами России по доле сельского населения колеблются от 3,9\% в Магаданской области до 70,8\% в Республике Алтай [14] и оказывают влияние на позиции региональных 
рынков труда.

О высокой межрегиональной дифференциации свидетельствует значительный разброс ключевых показателей российского рынка труда.

Так, по данным таблицы 1, максимальные и минимальные региональные значения уровня занятости и участия в составе рабочей силы различаются более, чем в полтора раза, среднемесячной номинальной заработной платы (июнь 2019г.) болеетрехсполовиной.Наиболеевысоким является 20-кратный межрегиональный разброс регионов по уровню безработицы. Устойчивые межрегиональные различия являются фундаментальной характеристикой российского рынка труда, которую необходимо полнее учитывать не только при проведении научного анализа, но и в практике управления на основе реализации регионально-дифференцированного подхода к разработке мер поддержки занятости населения. Однако столь разительные и устойчивые во времени контрасты остаются незамеченными при исследовании и эмпирической оценке среднероссийских значений ключевых показателей национального рынка труда. Основываясь на методах статистического анализа, была проведена классификация субъектов РФ, сформированы региональные кластеры, которые характеризуются разной ситуацией на рынке труда и существенными различиями значений его ключевых показателей. В выборку включено 85 регионов России, база данных сформирована на основе данных Росстата. Результаты классификации регионов представлены в Таблице 2.

Как свидетельствуют расчеты, субъекты РФ с максимальным и умеренно высоким уровнем безработицы составляют в региональной структуре рынка труда 40\%. На регионы с минимальным и умеренно низким уровнем безработицы приходится 37,7\%, в остальных $(22,3 \%)$ значения уровня безработицы колеблются вокруг среднероссийского. Обращает на себя внимание тот факт, что численность регионов с максимальным и умеренно высоким уровнем безработицы почти в два раза $(1,8)$ превышает число регионов срединной группы и на 6,3\% территории с умеренно и минимально низкими значениями. Это свидетельствует о неоднородности и асимметричности региональной структуры российского рынка труда, накопленных диспропорциях и наличии потенциальных рисков усиления социальной напряженности.

Высокий уровень безработицы отличает регионы с сильным демографическим давлением на рынок труда, где доля молодежи в возрастной структуре населения намного больше среднероссийской, слабо урбанизированные территории с высоким удельным весом сельского населения, а также территории монопрофильной

Таблица 1. Основные показатели функционирования российского рынка труда, май-июль 2019 г.

\begin{tabular}{|l|c|c|c|}
\hline \multicolumn{1}{|c|}{ Показатели } & $\begin{array}{c}\text { Среднероссий- } \\
\text { ское значение }\end{array}$ & Максимум & Минимум \\
\hline Уровень безработицы, \% & 4,5 & 26,0 & 1,3 \\
\hline Уровень занятости, \% & 59,4 & 78,4 & 47,5 \\
\hline Уровень участия в рабочей силе, \% & 62,2 & 83,1 & 53,0 \\
\hline $\begin{array}{l}\text { Среднемесячная номинальная начисленная заработная } \\
\text { плата, руб. }\end{array}$ & 49348 & 106909 & 27443 \\
\hline
\end{tabular}

Источник: составлено автором по данным Росстата [6,15]

Таблица 2. Классификация регионов России по уровню безработицы,\%

\begin{tabular}{|c|c|c|c|}
\hline № группы & Уровень безработицы, \% & Число регионов в группе & \% к общему числу регионов \\
\hline 1 & До 3,0\% & 5 & 5,9 \\
\hline 2 & $3,1 \%-4,0 \%$ & 27 & 31,8 \\
\hline 3 & $4,1 \%-5,0 \%$ & 19 & 22,3 \\
\hline 4 & $5,1 \%-6,0 \%$ & 14 & 4,5 \\
\hline 5 & $6,1 \%-7,0 \%$ & 4 & 18,8 \\
\hline 6 & $7,1 \%$ и более & 16 & 100 \\
\hline РФ & $4,5 \%$ & 85 & \\
\hline
\end{tabular}

Источник: расчеты автора по данным Росстата [6,14] 
специализации. Данные статистики подтверждают, что регионы с высокой долей молодежи в структуре населения относятся к сегментам повышенного риска на рынке труда, среди безработных молодежь до 25 лет составляет 26,3\% [6]. Уязвимой частью национального рынка труда следует назвать также сельские территории, регионы России с повышенной долей сельского населения отличаются высокими значения уровня и продолжительности безработицы. В то же время регионы с диверсифицированной структурой занятости и источников доходов населения, высокими показателями уровня экономического развития, удельного веса наукоемких производств и услуг в структуре экономики, а также более высокой долей лиц с высшим или средним профессиональным образованием, характеризуются низким уровнем безработицы. Исследования, проведенные ранее, свидетельствуют, что к факторам снижения рисков роста уровня и продолжительности безработицы, помимо указанных, можно отнести увеличение удельного веса домохозяйств, имеющих доступ к сети Интернет, а также расширение экспортной ориентации экономики региона.

Важным объяснением межрегиональных контрастов на рынке труда выступает специализация экономики региона, определяющая особенности структуры занятости. Различия в уровне образования населения влияют не только на дифференциацию индикаторов рынка труда, но и экономическое развитие региона. Нельзя исключать влияние «стартовых условий», а также комплекса институциональных, демографических, экономических и социальных факторов развития регионов России. Существенными являются различия между сырьевыми регионами и территориями с высокой долей обрабатывающих производств в структуре добавленной стоимости, регионами с узкоспециализированной и диверсифицированной экономикой и структурой занятости, аграрными, индустриальными и сервисными, а также центральными и периферийными. В результате указанных причин экономическая рецессия, также как и восстановительный рост по-разному затрагивают региональные рынки труда, определяя специфику поведенческих реакций. Сложившиеся под влиянием демографических, экономических, социальных, институциональных факторов межрегиональные контрасты и высокие транзакционные издержки смены работы и места жительства занятых и безработных сформировали предпосылки проявления эффекта «множественного равновесия», то есть наличия нескольких равновесных состояний на рынке труда. При этом различия затрагивают не только размеры заработной платы и условия найма, но и предпочтения в сфере занятости, стереотипы трудового поведения, неформальные институты, качество жизни населения. Эффект «множественного равновесия» на российском рынке труда, который отличает его от рынков труда в странах Европы, будет определять особенности функционирования в условиях экономической рецессии.

Глобальные тенденции экономического развития актуализируют задачи оценки и моделирования поведения региональных рынков труда России в новых условиях макроэкономических изменений. Прогнозируются низкие темпы роста мировой экономики в 2020 г., эксперты не исключают риски рецессии в 2021 г. На этом фоне важной задачей является поддержка занятости населения и создание новых рабочих мест в развивающихся секторах российской экономики. Вместе с тем процесс адаптации российского рынка труда к макроэкономическим изменениям будет иметь свои особенности и региональную специфику, формируя «эффекты асимметрии». Следует ожидать, что снижение темпов экономического роста, рецессия, также как и последующий восстановительный рост, асимметрично повлияют, прежде всего, на структуру фактической безработицы в регионах России, увеличивая или уменьшая долю циклического компонента. Масштабы роста уровня и продолжительность безработицы в период экономической рецессии в разной степени затронут региональные рынки труда. Асимметричные поведенческие реакции ключевых индикаторов российского рынка труда повлияют на изменение степени его межрегиональной дифференциации как в условиях экономической рецессии, так и последующего восстановительного роста.

Таким образом, особенности региональной структуры необходимо полнее учитывать при использовании инструментов регулирования рынка труда, разработке мер, направленных на поддержку занятости населения и сдерживания роста безработицы в условиях замедления темпов роста и нарастания экономической нестабильности. 


\section{Библиографический список}

1. Семерикова Е.В. Демидова О.А. Анализ региональной безработицы в России и Германии: пространственноэкономический подход // Пространственная экономика. 2015. № 2. С. 64-85.

2. Marelli E., Vakulenko E. Youth unemployment in Italy and Russia: Aggregate trends and individual determinants // The Economic and Labour Relations Review. 2016. № 27 (3). P. 387-405.

3. Choudhry M., Marelli E. and Signorelli M. Youth and the total unemployment rate: The impact of policies and institutions // International J. Manpower. 2012. № 33 (1). P. 76-95.

4. Семерикова Е.В. Демидова О.А. Взаимодействие региональных рынков труда в России: анализ с помощью пространственных эконометрических моделей // Пространственная экономика. 2016. № 3. С. 57-80.

5. Блинова Т.В., Былина С.Г., Русановский В.А. География молодежной безработицы в России // Вестник Московского университета. Серия 5. География. 2018. № 4. С. 93-100.

6. Росстат: Занятость и безработица в Российской Федерации июле 2019 года (по итогам обследования рабочей силы). URL -https://www.gks.ru/bgd/ free/b04_03/IssWWW. exe/Stg/d04/160.htm.

7. Российский рынок труда: тенденции, институты, структурные изменения. Коллективная монография. Под общ. ред. В.Е. Гимпельсона, Р.И. Капелюшникова, С.Ю. Рощина // М.: Центр стратегических разработок, 2017.

8. Marelli E., Patuelli R. and Signorelli M. Regional Unemployment in the EU before and after the Global Crisis // PostCommunist Economies. 2012. № 24 (2). P. 155-175.

9. Brada J.C., Marelli E., Signorelli M. Young People and the Labor Market: Key Determinants and New Evidence // Comparative Economic Studies. 2014. 56 (4). P. 556-566.

10. Blinova T., Bylina S., Rusanovsky V. Factors and Determinants of Interregional Unemployment Rate Differences in Rural Russia //Agricultural Sciences. 2016. № 7 (9). P. 630-641.

11. Blinova T., Markov V., Rusanovskiy V. Empirical Study of Spatial Differentiation of Youth Unemployment in Russia // Acta Oeconomica. 2016. № . 66 (3). P. 507-526.

12. Karaalp Orhan H.S. and Gülel F.E. Regional Unemployment in Turkey: A Spatial Panel Data Analysis // J. Social Security. 2016. № 2. P. 48-67.

13. Росстат: Оперативные показатели. URL - https://www.gks.ru.

14. Демографический ежегодник России. 2019: Стат.сб./Росстат. М., 2019. URL- http:// www. gks.ru

15. Росстат: Среднемесячная номинальная начисленная заработная плата работников по полному кругу организаций по субъектам Российской Федерации в 2019 году. URL- http://old.gks.ru/wps/wcm/connect/rosstat_ main/ rosstat/ru/statistics/wages/ 